\title{
Aplikasi Penampil Informasi Data Tanaman Mangrove Menggunakan $Q R$-Code di Hutan Mangrove Cilacap
}

\author{
Andriansyah Zakaria ${ }^{1 *}$, Andesita Prihantara ${ }^{2}$, Antonius Agung $\mathrm{H}^{3}$, Rostika Lystianingrum ${ }^{4}$, \\ Fadhillah Hazrina ${ }^{5}$ \\ 1,2,3,4Program Studi Teknik Informatika, Politeknik Negeri Cilacap, Indonesia \\ ${ }^{5}$ Program Studi Teknik Listrik Politeknik Negeri Cilacap, Indonesia

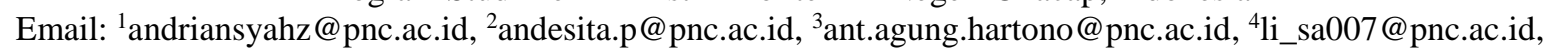 \\ ${ }^{5}$ fadhillahazrina@pnc.ac.id
}

\section{INFORMASI ARTIKEL}

\section{Data artikel:}

Naskah masuk, 29 September 2019

Direvisi, 31 Desember 2019

Diiterima, 16 Januari 2020

\section{Kata Kunci:}

Android

Edukasi

QR Code

Sistem informasi

Mangrove

\begin{abstract}
ABSTRAK
Abstract- EduWisata is a concept of developing an environmentally friendly tourism area by taking into accounts the resources and elements of education in a marine tourism package. The concept has been applied to the Cilacap mangrove forest area. The lack of information media in the mangrove forest area makes the visiting community still not get complete information about the types, classifications, benefits, and distribution of mangrove plants. Quick Response Code or also known as QR Code can be used as a media for storing information based on information technology in the form of a code image. The image of this code can be scanned using a QR code scanner. The QR Code system can also assist managers in improving the quality of service in the delivery of educational information on the types of mangrove plants found in mangrove forests to the public. The QR Code system is made using smartphone technology to scan QR codes. Mangrove plant data information will appear on the visitor's smartphone screen, so visitors will easily access information about mangrove plants.
\end{abstract}

Abstrak- EduWisata merupakan konsep pengembangan
kawasan pariwisata yang ramah lingkungan dengan
memperhatikan sumber daya dan unsur pendidikan dalam paket
wisata bahari, konsep tersebut telah diterapkan pada kawasan
hutan mangrove cilacap. Kurangnya media informasi di
kawasan hutan mangrove membuat masyarakat yang
berkunjung masih belum mendapatkan informasi secara
lengkap tentang jenis, klasifikasi, manfaat, dan sebaran
tanaman mangrove. Quick Response Code atau dikenal dengan
QR Code dapat digunakan sebagai media penyimpan informasi
berbasis teknologi informasi dalam bentuk citra kode, citra
kode ini dapat dipindai menggunakan pemindai kode QR.
Sistem QR Code juga dapat membantu pengelola dalam
meningkatkan kualitas pelayanan dalam penyampaian
informasi edukasi jenis tanaman mangrove yang terdapat di
hutan mangrove kepada masyarakat. Sistem QR Code yang
dibuat memanfaatkan teknologi smartphone untuk memindai
kode QR. Informasi data tanaman mangrove akan tampil pada


layar smartphone pengunjung, dengan begitu para pengunjung akan dengan mudah mengakses informasi tentang tanaman mangrove.

\section{Korespondensi:}

\section{Andriansyah Zakaria}

Program Studi Teknik Informatika, Politeknik Negeri Cilacap

J1. Dr. Soetomo No.1 Karangcengis, Sidakarya Cilacap, Indonesia

\section{PENDAHULUAN}

Dengan berkembangnya teknologi informasi dan komunikasi yang semakin pesat, membuat kebutuhan akan kecepatan dan ketersediaan akses akan informasi semakin penting. Salah satu kemajuan teknologi tersebut adalah penggunaan smartphone. Salah satu pemanfaatan smartphone dapat digunakan sebagai pemindai guna penyampaian suatu informasi dengan cepat menggunakan Quick Response Code (QR Code) atau dapat disebut juga dengan kode respon cepat (Sugiantoro \& Hasan, 2015).

QR Code merupakan matriks kode batang atau kode dua dimensi yang dapat menyimpan informasi data dan dirancang untuk dapatt dibaca menggunakan smartphone (Tiwari, 2017). QR merupakan kepanjangan dari "Quick Response" yang artinya isi kode harus diterjemahkan dengan cepat. Kode tersebut terdiri dari modul-modul hitam yang tersusun dalam kotak pola pada latar belakang putih. Informasi yang disandikan dapat berupa teks, URL, atau data lainnya (Sutheebanjard \& Premchaiswadi, 2010). Untuk dapat membaca informasi yang tersimpan dapat menggunakan pemindai $\mathrm{QR}$ ataupun dapat menggunakan smartphone yang telah terpasang aplikasi pemindai QR. QR Code dapat digunakan untuk aplikasi berbasis android smartphone, seperti promosi produk, informasi alamat situs suatu perusahaan, identifikasi suatu produk dan sebagainya (Prathivi, 2018).

Mangrove merupakan jenis tumbuhan yang memiliki kemampuan beradaptasi pada kondisi lingkungan yang ekstrim, seperti pada tanah yang tergenang, lingkungan air dengan kadar garam tinggi, dan kondisi tanah yang tidak stabil. Tumbuhan mangrove tumbuh di daerah pasang surut seperti pada laguna, muara sungai dan daerah terlindung. Hutan mangrove lebih dikenal dengan sebutan hutan bakau yang merupakan salah satu jenis tumbuhan yang menyusun ekosistem hutan mangrove (Pratama \& Isdianto, 2017).

Hutan mangrove di Indonesia mempunyai banyak sekali manfaat baik dari aspek ekonomi, sosial, dan ekologi. Habitat yang terdapat pada hutan mangrove lebih bervariasi dibanding dengan hutan daratan, dikarenakan adanya interaksi komponen penyusun ekosistem yang kompleks. Ekosistem yang terdapat pada hutan mangrove tidak terpengaruh iklim, melainkan sangat terpengaruh oleh faktor edafis dalam pembentukan ekosistemnya (Poedjirahajoe, Marsono, \& Wardhani, 2017).

Kabupaten Cilacap memiliki hutan mangrove dengan luas sekitar $10 \mathrm{Ha}$ yang merupakan kawasan terluas di pulau jawa. Kawasan hutan mangrove ini dikelola oleh Lembaga Masyarakat Desa Hutan (LMDH) dan dinas Perhutani Cilacap (Suryono, 2006). Hutan mangrove Cilacap berada di Kelurahan Tritih Kulon, Kecamatan Cilacap Utara, Kabupaten Cilacap. Keberadaan hutan mangrove sangat berpengaruh positif bagi kelestarian ekosistem, serta dapat mencegah terjadinya abrasi, pasang air laut akibat perubahan iklim ataupun cuaca buruk (Soleh, Rachim, \& Humaedi, 2016).

Koleksi tanaman mangrove Cilacap terdiri dari 40 jenis tanaman mangrove seperti tancang (bruguiera gymnorrhiza), api - api (avicennia sp), bakau bandul (rhizophora mucronata), bakau kacangan (rhizopora apiculata), dan lain - lainnya (Setyawan, 2003). Banyak masyarakat yang belum mengetahui keanekaragaman jenis mangrove, manfaatnya, sebarannya dikarenakan media edukasi untuk menyampaikan informasi mengenai jenis tanaman mangrove masih sangat kurang. Selama ini media penyampaian informasi hanya disampaikan langsung oleh pemandu wisata secara verbal sehingga hal tersebut masih dirasa kurang untuk 
mendukung kawasan hutan mangrove sebagai kawasan edu wisata yang merupakan merupakan kawasan yang tidak hanya sebagai destinasi wisata keluarga yang ramah lingkungan melainkan juga sebagai kawasan yang dapat dijadikan sarana edukasi mengenal jenis tanaman mangrove dari manfaat, sebaran, dan lain-lainnya guna meningkatkan rasa kepedulian terhadap lingkungan sekitar.

Berdasarkan hasil riset awal yang dilakukan di lokasi kawasan hutan mangrove, salah satu cara yang dapat diaplikasikan untuk membantu pihak pengelola untuk meningkatkan kualitas pelayanan dalam menyampaikan informasi tanaman mangrove kepada mayarakat atau pengunjung adalah dengan membuat sebuah aplikasi android dengan memanfaatkan smartphone yang digunakan sebagai alat pindai QR Code yang dapat menampilkan informasi dari jenis-jenis tanaman mangrove.

\section{METODE PELAKSANAAN}

Metode yang digunakan pada kegiatan pengabdian kepada masyarakat ini ada 6 (enam) tahapan, yaitu observasi lapangan, wawancara, uji coba aplikasi, pelatihan penggunaan aplikasi, dan evaluasi.

1) Observasi Lapangan: observasi dilakukan di Hutan Payau Cilacap, Kelurahan Tritih kulon, Kecamatan Cilacap Utara, Kabupaten Cilacap. Observasi dilakukan guna mengetahui potensi wilayah dan permasalahan yang mungkin dapat diatasi melalui kegitan pengabdian.

2) Wawancara kepada pihak terkait: kegiatan wawancara dilakukan guna memperoleh informasi aktual dan terkini terkait kebutuhan teknologi spesifik lokasi yang dilakuakn oleh masyarakat. Wawancara dijadikan sebagai dasar penentu program pengabdian yang akan dilaksanakan. Hal ini ditujukan agar program pengabdian tepat sasaran dan memberikan manfaat bagi masyarakat.

3) Pembuatan dan uji coba aplikasi: data yang diperoleh saat wawancara dan diskusi digunakan sebagai dasar pertimbangan dalam pembuatan aplikasi. Sebelum aplikas dapat diterapkan, terlebih dahulu dilakukan serangkaian uji coba untuk mengetahui kemungkinan terjadinya kesalahan atau pun kegagalan sistem yang ada sehingga dapat segera diaplikasikan.

4) Pelatihan penggunaan aplikasi: setelah apliksi selesai dibuat dan diuji cobakan maka, akan dilaksanakan pelatihan dan sosialisasi penggunaan aplikasi berbasis QR kepada penanggung jawab Hutan Payau beserta perwakilan masyarakat.

5) Evaluasi: pada tahap ini dilakukan kegiatan monitoring pasca pelatihan terkait kegiatan pembuatan aplikasi edukasi tanaman mangrove. Kegiatan evaluasi dilaksanakan untuk mengetahui keberlanjutan program di masyarakat penerima program. Monitoring program dilaksanakan bekerja sama dengan LMDH Mangrove Cilacap.

\section{HASIL DAN PEMBAHASAN}

Hasil pengamatan vegetasi tanaman mangrove di lokasi pengabdian secara keseluruhan disimpulkan terdapat 16 jenis tanamana mangrove yang menyusun populasi Hutan Mangrove Cilacap. Jenis-jenis tersebut adalah Acanthus Ebractatus, Avicennia Alba, Avicennia Marina, Bruguiera Cylindrica, Brugiera Gymnorhiza, Brugiera Sexangula, Ceriops Candolleana-Ceriopas Tagal, Ceriops Decandra-Ceriops Roxburghiana, Lumnitzera Racemosa, Nypa Fructicans, Rhizopora Apiculata, Rhizopora Mucronata, Sonneratia Alba, sonneratia Caseolaris, Xylocarpus Granatum, dan Xylocarpus Moluccensis.

Pengembangan wisata Hutan Mangrove sebagai sumber edukasi bagi masyarakat perlu dibangun segera mungkin, salah satunya melalui pengenalan jenis tanaman mangrove kepada masyarakat dan pengunjung hutan payau. Pengenalan tanaman mangrove dapat dilakukan dengan memanfaatkan teknologi QR Code dengan smartphone sebagai alai pindai. Masing-masing QR Code memuat informasi jenis tanaman mangrove, kemudian masyarakat menggunakan smartphone untuk melakukan pindai kode tersebut. Informasi data tanaman mangrove tertentu akan tampil pada layar smartphone pengunjung.

\subsection{Perancangan Sistem Aplikasi}

Sistem aplikasi yang diusulkan terdiri dari tiga bagian, yaitu website sebagai penampung informasi tanaman mangrove, $\mathrm{QR}$ Code generator yang digunakan untuk menyimpan 
dan membuat kode QR. URL masing-masing halaman tanaman mangrove pada website akan digunakan untuk pemberian informasi pembuatan kode QR.

Bagian selanjutnya QR Code Scanner yang merupakan aplikasi pemindai kode QR berbasis android dengan memanfaatkan kamera smartphone. Pengunjung memindai kode QR tanaman mangrove yang terdapat pada poster yang tersedia pada lokasi wisata hutan mangrove menggunakan smartphone yang terpasang aplikasi pembaca kode QR, selanjutnya informasi mengenai tanaman mangrove tertentu akan ditampilkan pada layar smartphone sesuai dengan kode $Q R$ yang dipindai. Gambar 1 menunjukkan flowchart aplikasi QR Code.

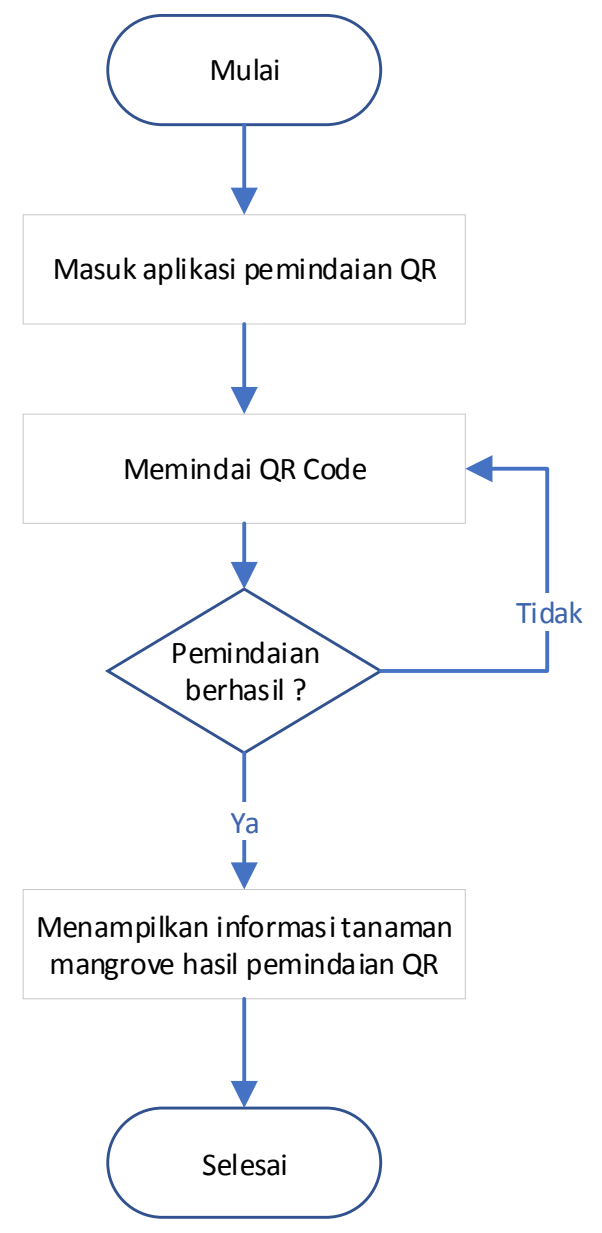

Gambar 1. Flowchart aplikasi QR Code

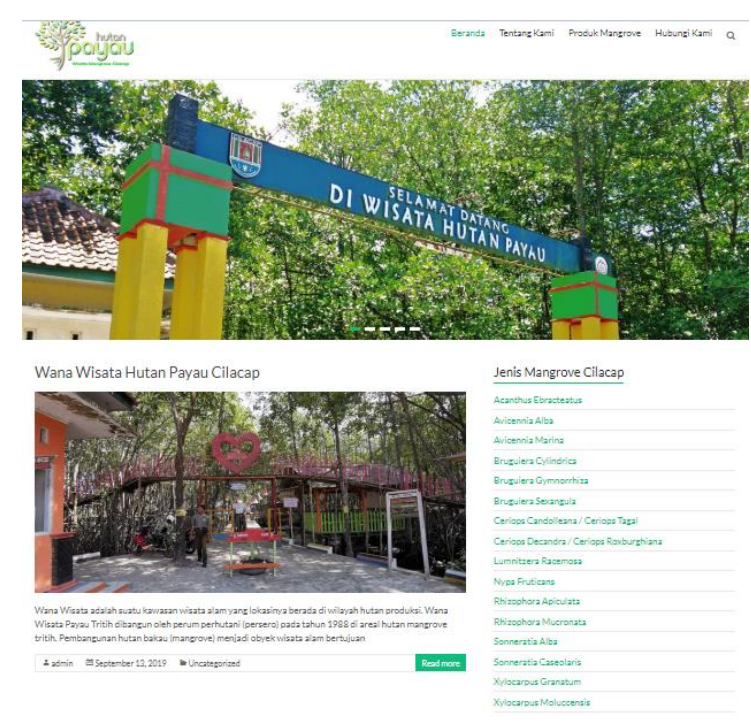

Gambar 2. Tampilan website wisata mangrove Cilacap pada perangkat desktop

\subsection{Hasil Pengujian Sistem}

Berikut merupakan hasil pengujian aplikasi penampil informasi tanaman mangrove menggunakan QR Code. Pengujian pertama dilakukan pada tampilan website wisata mangrove cilacap. Gambar 2 menunjukkan tampilan website pada perangkat desktop.

Gambar 3 menunjukan tampilan website pada perangkat smartphone. Website digunakan sebagai penampung informasi dari masing-masing jenis tanaman mangrove yang ada di wisata mangrove cilacap. Selanjutnya url halaman website dari setiap jenis tanaman mangrove yang ada digunakan untuk membuat kode QR. Proses tambah kode QR ditunjukkan pada Gambar 4, serta Gambar 5 merupkn penggmbarn kode $\mathrm{QR}$ yang dihasilkan aplikasi. Pada Gambar 6 menunjukkan dashboard dari aplikasi QR Code Generator yang dibuat. 

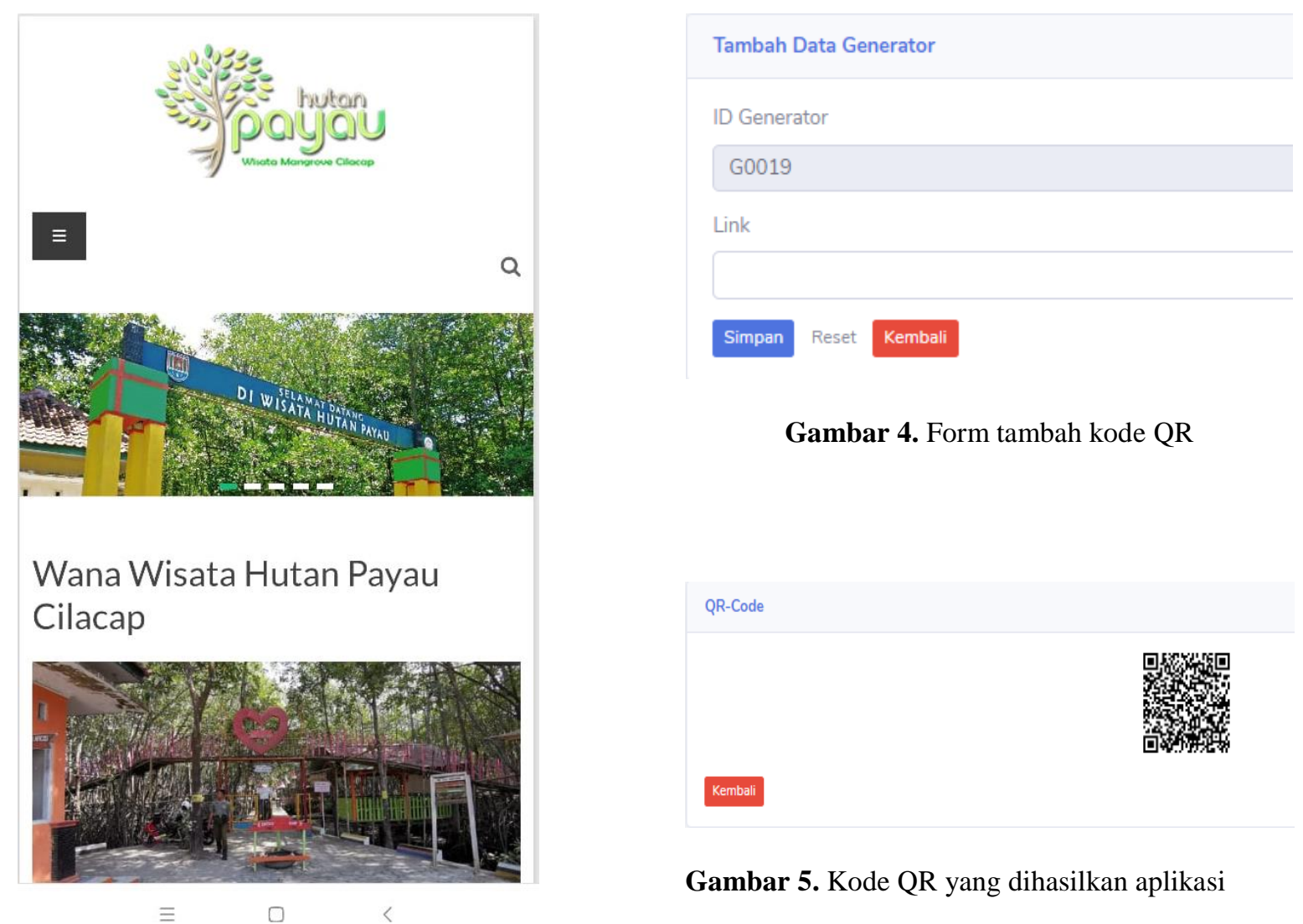

Gambar 4. Form tambah kode QR

\section{Gambar 5. Kode QR yang dihasilkan aplikasi}

Gambar 3. Tampilan website pada smartphone

\begin{tabular}{|c|c|c|c|c|c|c|c|}
\hline \multicolumn{8}{|c|}{$\begin{array}{l}\text { Generator QR-Code } \\
\text { Tambah Data }\end{array}$} \\
\hline ID Generator & $\uparrow$ & Link & & Aksi & & & \\
\hline 1. & & https://goo.gl/maps/RzN8vQ3o1Eda1sY78 & & & Ubah Data & QR-Code & Hapus \\
\hline 2 . & & https://mangrove-cilacap.or.id/acanthus-ebracteatus/ & & & Ubah Data & QR-Code & | Hapus \\
\hline 3. & & https://mangrove-cilacap.or.id/avicennia-alba/ & & & Ubah Data & QR-Code & Hapus \\
\hline 4 & & https://mangrove-cilacap.or.id/avicennia-marina/ & & & Ubah Data & QR-Code & Hapus \\
\hline
\end{tabular}

Gambar 6. Dashboard aplikasi QR Code Generator 


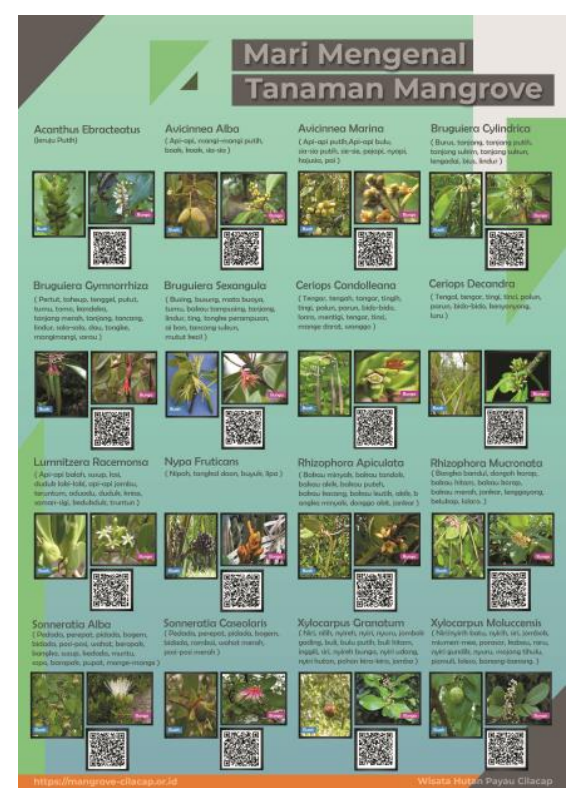

Gambar 7. Poster mari mengenal tanaman mangrove

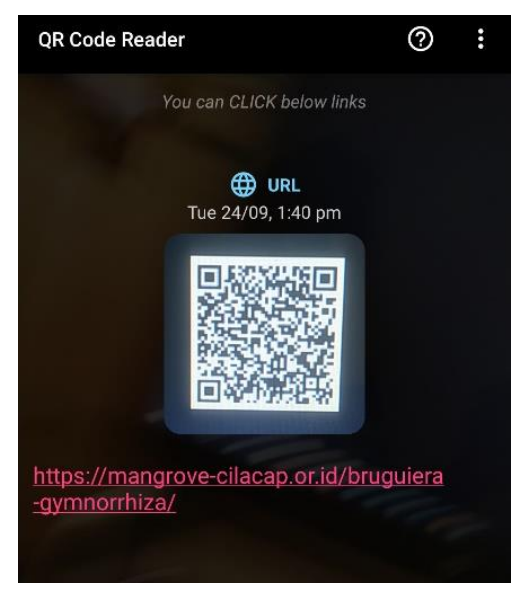

Gambar 8. Kode QR berhasil dibaca pemindai

Dari kode QR yang dihasilkan dibuat media poster yang digunakan sebagai sarana informasi di tempat wisata, sehingga pengunjung bisa yang ingin mengetahui lebih detail dari tanaman mangrove tertentu bisa memindai kode QR yang ada. Gambar 7 menunjukkan media poster mengenal tanaman mangrove. Kode QR yang dihasilkan bisa dibaca oleh semua aplikasi pemindai QR Code yang menggunakan bantuan kamera smartphone. Gambar 8 menunjukkan kode QR yang berhasil dibaca oleh pemindai QR Code.
Setelah kode QR terbaca, pengguna bisa menekan url yang dihasilkan, dan pengguna akan dialihkan pada website sesuai dengan url yang dihasilkan, seperti pada Gambar 9. Kode QR yang dihasilkan dapat terbaca dengan baik oleh semua aplikasi pemindai QR Code yang tersedia di playstore.

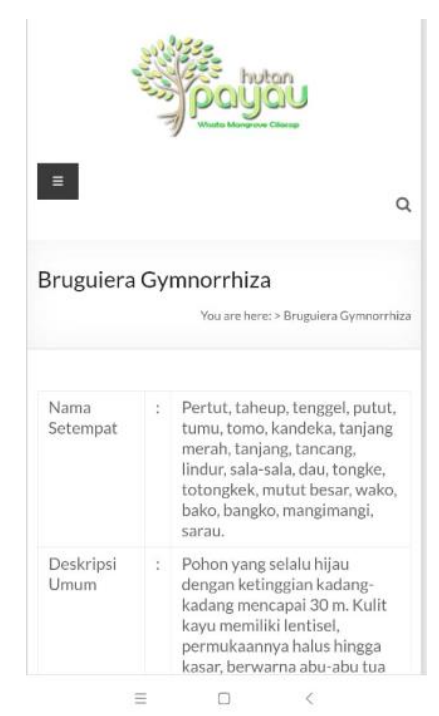

Gambar 9. Informasi tanaman mangrove dari kode QR

\section{KESIMPULAN}

Dari hasil dan pembahasan kegiatan pengabdian kepada masyarakat mngenai aplikasi penampil informasi tanaman mangrove menggunakan QR Code di wisata hutan mangrove cilacap dapat disimpulkan, dengan adanya aplikasi ini dapat dijadikan salah satu solusi yang efektif dari permasalahan kurangnya media penyampai informasi dan edukasi mengenai jenis tanaman mangrove kepada pengunjung wisata hutan mangrove cilacap dalam rangka tercapainya konsep Edu-Wisata. Selain itu perlu adanya wisata edukasi pengenalan tanaman mangrove secara fisik, sehingga pengunjung bukan hanya sekedar tahu secara lisan melainkan juga bisa mengetahui secara nyata.

\section{UCAPAN TERIMA KASIH}

Kami mengucapkan terimakasih kepada Politeknik Negeri Cilacap yang telah memberikan pendanaan kegiatan ini, serta 
ketua LMDH Purwa Lestari dan masyarakat sekitar atas partisipasi dan dukungan dalam pelaksanaan kegiatan pengabdian kepada masyarakat.

\section{DAFTAR PUSTAKA}

Poedjirahajoe, E., Marsono, D., \& Wardhani, F. K. (2017). Penggunaan Principal Component Analysis dalam Distribusi Spasial Vegetasi Mangrove di Pantai Utara Pemalang. Jurnal Ilmu Kehutanan, 11(1), 29. https://doi.org/10.22146/jik.24885

Pratama, L. W., \& Isdianto, A. (2017). Pemetaan Kerapatan Hutan Mangrove Di Segara Anakan, Cilacap, Jawa Tengah Mengunakan Citra Landsat 8 Di Lembaga Penerbangan dan Antariksa Nasional (Lapan), Jakarta. Jurnal Floratek, 12(1), 57-61.

Prathivi, R. (2018). Analisa Sistem Qr Code Untuk Identifikasi Buku Perpustakaan. Pengembangan Rekayasa Dan Teknologi, 14(2), 37-40.

SETYAWAN, A. D. (2003). Mangrove ecosystem in Java: 1. recent status. Biodiversitas, Journal of Biological Diversity, 4(2), 130-142. https://doi.org/10.13057/biodiv/d040211

Soleh, I., Rachim, H. A., \& Humaedi, S.
(2016). Pengembangan Masyarakat Melalui Pelestarian Hutan Mangrove Oleh Kelompok Tani Patra Krida Wana Lestari Dikecamatan Kampung Laut Kabupaten Cilacap. Prosiding Penelitian Dan Pengabdian Kepada Masyarakat, 3(2).

https://doi.org/10.24198/jppm.v3i2.13651 Sugiantoro, B., \& Hasan, F. (2015). Pengembangan Qr Code Scanner Berbasis Android Untuk Sistem Informasi Museum Sonobudoyo Yogyakarta. Telematika, 12(2), 134-145. https://doi.org/10.31315/telematika.v12i2 .1410

Suryono, C. A. (2006). Struktur Populasi Vegetasi Mangrove di Laguna Segara Anakan. 11(2), 112-118.

Sutheebanjard, P., \& Premchaiswadi, W. (2010). QR-code generator. Proceedings - 2010 8th International Conference on ICT and Knowledge Engineering, ICT and KE 2010, (November 2010), 89-92. https://doi.org/10.1109/ICTKE.2010.569 2920

Tiwari, S. (2017). An introduction to QR code technology. Proceedings - 2016 15th International Conference on Information Technology, ICIT 2016, 1, 39-44. https://doi.org/10.1109/ICIT.2016.38 